\title{
MUJERES LEVANTÁNDOSE CON LA IGLESIA MORAVA, LA GUERRA Y LOS ONGS
}

Laura Hobson de Herlihy ${ }^{[1]}$

\section{Resumen}

Este artículo se centra en la situación actual de las mujeres indígenas y afrodescendientes y la participación política y su acceso a puestos de liderazgo. La investigación exploró el proceso desde el cual las mujeres miskitu y kriol en Nicaragua han catapultado posiciones de liderazgo en el grupo matrilocal en altos cargos políticos. Los datos recogidos en Bilwi-Puerto Cabezas demuestra que mujeres las miskitu y kriol lideresas en los últimos 30 años han accedido a puestos de liderazgo político a través de su participación con la Iglesia Morava, la revolución sandinista, y después de 1990 las organizaciones de desarrollo. Estas etapas de empoderamiento pueden combinarse para favorecer el liderazgo de mujeres.

Palabras clave: mujeres indígenas y afrodescendientes; liderazgo político; iglesia, revolución, desarrollo, feminismo.

\section{Summary}

This article focuses on the current situation of indigenous and afrodescendant women, their political participation and access to leadership posts. The research explored the process from which the Miskitu and Creole women in Nicaragua have catapulted leadership positions in the matrilocal group in high political posts. Data collected in Bilwi-Puerto Cabezas shows that Miskitu and Creole women leaders, in the past 30 years have had access to political leadership positions through their involvement with the Moravian Church, the Sandinista revolution, and after 1990 due to the development organizations. These stages of empowerment can be combined to promote women leadership.

Keywords: Indigenous and afrodescendant women, political leadership, church, revolution, development, feminism.

[1] University of Kansas, Ph.D., Anthropology 


\section{Introducción}

Cuando llegué por primera vez a Bilwi-Puerto Cabezas, Nicaragua, la capital de la Región Autónoma del Atlántico Norte, con una población de 58,00o habitantes. Me llamó la atención la alta visibilidad de las mujeres en la posición profesional y política. Las mujeres sirviendo como rectores de universidades, profesores, directores de organizaciones no gubernamentales, las mujeres congresistas, jueces, abogados. $\mathrm{Me}$ enteré de que la mujer entró por primera vez a los puestos de dirección después de la concesión de la comunidad autónoma. De hecho, los sandinistas inspiraron a mujeres de la minoría en el año 1987 mediante la selección de Myrna Cunningham como la primera gobernadora de la Costa del Atlántico Norte. Los sandinistas, principalmente las mujeres criollas, seleccionadas como lideresas en la región autónoma, era como premiarlas a ellas, por así decirlo, por su lealtad al partido sandinista durante los años revolucionarios y la guerra de la década de 1980. Es cierto que las mujeres criollas estaban más preparadas que las mujeres de la minoría, para asumir nuevos roles como lideresas, ya que históricamente han mantenido un alto estatus socio-económico y tuvieron más acceso a la educación que los miskitus, sumus mayangnas, garífunas y los vecinos de la Costa Caribe (Gabbert, 2006).

Sin embargo, en el momento de mi estudio en el período 2006-2007, las mujeres indígenas Mískitos de YATAMA y otros partidos políticos, como el PLC, fueron impresionantes rompiendo las barreras políticas. Nancy Elizabeth Enríquez fue elegida alcalde de Puerto Cabezas, Rosa Wilson fue elegida Sindica (Administradora de los recursos naturales de la comunidad) de Puerto Cabezas y se desempeñó como presidenta de la poderosa organización política Diez Comunidades el cual controla las finanzas de los recursos de propiedad comunal de la RAAN. Quizá lo más importante fue que Cora Antonio fue nombrada superintendente de la Iglesia Morava de Nicaragua. Las mujeres criollas alineadas con los sandinistas continuaron entrando a cargos públicos de liderazgo. Raquel Dixon por ejemplo, fue elegida como uno de los tres representantes de la RAAN ante la Asamblea Nacional de Nicaragua. Tanto criollas como mujeres miskitus dirigían agencias gubernamentales, tales como el Ministerio de Salud (MINSA) y las comisiones de los gobiernos municipales y regionales.

Como mis intereses eran ver el progreso en el liderazgo de las mujeres en Nicaragua, me di cuenta de que, al mismo tiempo que las mujeres eran cada vez más visibles en el espacio público y como lideresas cívicas y políticas, su participación global en la región autónoma del norte era de una visibilidad creciente en cuanto a ser lideresas, pero disminuían en cuanto a la participación en el gobierno regional, y por esa razón se convirtió en el foco principal de esta investigación.

En Bilwi-Puerto Cabezas, terminé la investigación etnográfica y entrevistó a veinticinco mujeres que eran de aspectos del gobierno, religiosas y lideresas de la sociedad civil. 
Mi investigación y las entrevistas se centraron en los factores que han facilitado el ascenso de mujeres indígenas y afrodescendientes para un cargo público, así como el factor que impide su acceso a puestos de liderazgo, especialmente en el gobierno regional. Los factores que han contribuido a la participación de las mujeres en la RAAN como lideresas seria en presentar un estudio de caso convincente, donde las mujeres indígenas y afrodescendientes se están levantando, desplazando su dominio legítimo del poder del matrigrupo a la arena política. Los factores que han afectado el liderazgo de las mujeres es reflejar la minoría de desafíos que enfrentan las mujeres en su afán por democratizar la participación política dentro del Estado-nación en latinoamericana. El análisis de los datos ayudará a determinar la postura de las mujeres, de su propio empoderamiento y la opresión, ampliando así nuestra comprensión del movimiento de mujeres en la RAAN y un feminismo emergente indígena en la Costa Atlántica de Nicaragua. Me refiero al feminismo indígena como un nuevo tipo de feminismo transnacional, que destaca la combinación de los derechos individuales y colectivos a la cultura, el idioma, la tierra y los recursos.

\section{Factores a favor de las mujeres: liderazgo matrifocal}

Los antropólogos tienen una matrilocalidad detallada entre los misquitos de Nicaragua. García (1996), Helms (1971) y Peter (2002) observaron que la residencia post-marital entre Nicaragua y los miskitu es matrilocal, donde las mujeres pasan por el idioma miskitu y las prácticas de crianza a los niños mientras los hombres están fuera trabajando buscando los salarios en actividades laborales. Las Mujeres miskitu generalmente se mueven en sus propios hogares después de tener hijos, pero la familia de la mujer es parte de una matrigrupo grande bajo el control de una abuela o "kuka" (Herlihy, 2006, $2007,2012)$. Sonia Pedro afirma que hoy en día, las mujeres en la RAAN siguen criando a sus hijos sin un hombre en el papel de marido-padre, y que unos treinta y cinco por ciento de los hogares en Puerto Cabezas, están encabezadas por mujeres. Pedro afirmó que el elevado número de hogares encabezados por mujeres en las comunidades de la RAAN se puede atribuir a los migrantes el trabajo asalariado y de los un mil, siete centenares de hombres que murieron en la revolución y la guerra de los contras.

Los criollos tienen el nivel más alto de hogares encabezados por mujeres en la costa y viven en hogares multi-generacionales, de familias extendidas que están encabezadas por abuelas (CEIMM, 2008, p. 4). Las mujeres lideresas criollas y miskitus entrevistadas, ante todo, mencionan que se plantean en un grupo doméstico femenino centrado los ayudó a convertirse en lideresas. Muchas mujeres afirmaron haber adquirido y desarrollado sus habilidades de liderazgo observando las mujeres mayores en su rol de jefes de familia.

Las mujeres criollas tanto indígenas y afrodescendientes viven en grupos matrifocales domésticos donde las mujeres hacen decisiones económicas en el hogar y de la crianza y del niño, lo que sugiere una cultura matrifocal regional existe. Las mujeres 
Costeñas y su condición de estar atados a sus roles de madres y lideresas de la familia, de manera similar a las relaciones de poder de género en las sociedades caribeñas. Las mujeres afrocaribeñas tienen puntos de vista de liderazgo a menudo se involucran en conceptos de familia y la comunidad y la corbata en su ideología de género femenino, dominante, incluyendo lo que significa ser una mujer, madre, hija, hermana y (Collins, 1994). Mohammed (1986) y Wekker (2006) han observado que las mujeres del Caribe tienen una visión basada en la madre de liderazgo y empoderamiento. Estos puntos de vista divergentes de la potenciación del feminismo occidental y alinearse con el pensamiento feminista negro, revelando una característica definitoria del feminismo indígena a lo largo de la Costa Atlántica de Nicaragua.

\section{La Iglesia Morava}

Muchas mujeres lideresas entrevistadas me relataron que la Iglesia Morava ha jugado un papel clave en la promoción de las mujeres. Yolanda Dimitri afirmó que en la década de 1970 la Organización de mujeres Moravas ha abierto espacios para mujeres criollos y miskitu a capacitarse en las áreas de educación y salud, que los preparó para convertirse en educadores, enfermeras y lideresas en sus iglesias locales. Dimitri explicó que a las mujeres se les permitió tomar el púlpito como pastores en las iglesias desde la década de 1990 y, desde entonces, han ascendido en la jerarquía.

La Iglesia Morava ha dado a las mujeres oportunidades de progreso profesional, a nombrado a Cora Antonio en 2007 para el cargo de superintendente de toda Nicaragua. Sin embargo, los líderes de la Iglesia Morava siguen teniendo ideologías machistas. La Iglesia Morava cree que la mujer es inferior al hombre, que su principal función es atender a su marido y a sus hijos, y que una mujer se les debe enseñar el comportamiento apropiado y corregido por su marido (Herman, 2006, pp. 81-83). A pesar de que la iglesia Morava ve a los hombres dominantes con sus puntos de vista sobre el género y el poder, los líderes de las mujeres entrevistadas afirmaron que experimentan que las mujeres llegaron a la costa casi un siglo después que los moravos. La presencia a largo plazo les ha proporcionado una alternativa a las estructuras patriarcales y la más rígida jerarquía de la Iglesia Católica.

\section{La Revolución Sandinista}

Nicaragua se convirtió en un modelo para la equidad de género en América Latina, después de las ganancias que se produjeron por los derechos de la mujer durante la revolución sandinista (Chinchilla, 1994). En 1979, bajo el nuevo Sandinista, el gobierno de Nicaragua por primera vez asumió la responsabilidad por la salud y la educación de la región costera marginada, significativamente ayudar a madres solteras que luchan por criar y cuidar a sus hijos y nietos. También abolió la distinción entre hijos legítimos e ilegítimos. El movimiento sandinista, entonces, conectado con criollos y 
mujeres miskitu por su ideología de género que valora la maternidad y no asume la presencia un marido-padre en el hogar.

Una de las partes más llamativas de la revolución fue la participación de las mujeres con la revolución, incluyendo su participación política y su mayor acceso a puestos de dirección política (Randall, 1981). Atlantic Coast mujeres contribuyendo radicalmente a la revolución y la guerra. Las mujeres sirvieron el casi el 30 por ciento de los combatientes militares en el lado sandinista, entre 7 y 15 en el lado contrarevolucionario; empero, muchas contribuyeron como enfermeras, proveedoras de información, y otra función de apoyo de la revolución y de la lucha por la autonomía (Davis, 2006; Kampwirth, 2001). Las mujeres también contribuyeron al proceso de paz y varios desempeñaron papeles oficiales sobre la comisión autónoma, establecida durante las negociaciones de paz entre el gobierno nacional sandinista y los contras.

Las lideresas mujeres de la RAAN entrevistadas subrayaron la importancia de la revolución sandinista como un factor importante que les permitió desempeñar papeles más destacados como lideresas y funcionarios públicos. El hecho de que en la década de 1980, las mujeres asumieron gran parte de la preservación de la cultura miskitu y la vida social y asumiendo nuevas funciones visibles en el hogar.

Las Mujeres de la RAAN también hizo hincapié en que el sandinismo ofrecía a las mujeres la igualdad de acceso a la educación para la primera vez. Esta educación prepara a las mujeres a convertirse en profesionales y lideresas políticas y cívicas.

La revolución sandinista hizo progreso de la educación disponible para todas las mujeres de la Costa Atlántica, incluidos los de diferentes orígenes étnicos y afinación a un partido político. La mujer de la RAAN particularmente han sido beneficiadas del Programa de Educación Intercultural Bilingüe (PEBI) con la enseñanza del idioma indígena. Mencionó que los sandinistas han ayudado a ser la Universidad pluriétnica de las Regiones Autónomas de la Costa Caribe (URACCAN), donde casi el 50 por ciento de los administradores, los profesores, y los estudiantes son mujeres, y dos mujeres, Myrna Cunningham fue seguida por Alta Hooker, han mantenido la posición más alta de la rectoria desde que la universidad fue fundada en 1994. Finalmente, el elevado nivel de ausentismo masculino durante los años de la guerra, promoviendo a las mujeres en puestos de liderazgo, y con la democratización del modelo educativo preparado para estas nuevas funciones.

\section{Post-ONG}

Los programas gubernamentales se retiraron de la región de la Costa Atlántica tras la derrota electoral de 1990 de los sandinistas. Al mismo tiempo, las políticas neoliberales económicas y extremas medidas de ajuste estructural que surgió forzando recortes en el sector público (Méndez, 2005). Las madres solteras, abandonadas por el Estado, 
fueron llamadas a prestar más servicios de salud y educación para sus hijos. Si bien las condiciones de pobreza prosperó, las ONG y las organizaciones de desarrollo en marcha con proyectos en la región para sustituir a los programas del gobierno (Babb, 2001). Las Mujeres en la RAAN dieron la bienvenida a la ayuda y se han beneficiado enormemente de muchas organizaciones no gubernamentales y los programas de la sociedad civil, especialmente organizaciones de mujeres de Yatama, La Asociación de Mujeres Indígenas de la Costa Atlántica (AMICA), y las organizaciones de mujeres Sandinista, el Movimiento de Mujeres Nidia White, Gaviota, una organización basada en CIDCA, y CEIMM (Centro de Estudios e Información de Mujeres Multietnicas) que es parte de la URACCAN.

Las mujeres lideresas de la RAAN entrevistadas afirman que las ONG han promovido las mujeres como lideresas porque han seleccionado principalmente para convertirse en directoras de sus organizaciones. Mujeres miskitus, afrodescendientes, y mayangna fueron seleccionados como directoras del más alto perfil en las organizaciones no gubernamentales en la RAAN, incluyendo el Centro de Investigación y Documentación de la Costa Atlántica de Nicaragua (CIDCA), Centro de Derechos Humanos Ciudadanos y Autonomicos (CEDEHCA); Programa de las Naciones Unidas para el Desarrollo (PNUD), el Plan Mundial de Alimentos (PMA), Cruz Roja (Red Cross), Casa de Cultura Tininiska (Tininiska Casa de la Cultura) y el Fondo de las Naciones Unidas Para La Infancia (UNICEF). Mujeres criollas desde la década de 1990 en general se han mantenido más direcciones de las ONG y organizaciones gubernamentales que mujeres miskitu. Sin embargo, esto comenzó a cambiar.

Durante las entrevistas con los directores de las organizaciones no gubernamentales y las mujeres en cargos públicos, muchas mujeres me dijeron que las ONG, así como el gobierno nacional, prefieren trabajar con las mujeres porque han visto como las mujeres de la RAAN son más responsables con el dinero, y menos corruptas, que los hombres de la localidad. Debby Hodgson afirmó: "hubo hombres como consejeros previamente, pero tenían demasiadas novias y gastaban demasiado dinero para entretenerlas". También comentó que las universidades, URACCAN y la financiación privada Bluefiuelds Índian and Caribbean University (BICU), han dado a las mujeres de la RAAN el mismo acceso a la educación que los hombres. Y añadió: "Somos tan educadas ahora y más responsable, por lo que hacer un mejor trabajo." Hodgson pasó a explicar que las personas con títulos universitarios, las mujeres tienden a permanecer a nivel local, ya que son los proveedoras de atención primaria y económicas para sus miembros de la familia.

La participación de las mujeres con las ONG representa un cambio general de las mujeres en Nicaragua y en América Latina, que cada vez más están asumiendo responsabilidades asumidas anteriormente por organismos estatales. A pesar de la negativa situación económica y política que ha creado la necesidad de que las mujeres 
trabajen con programas de las ONG, la participación de las mujeres con las ONG a lo largo de la Costa Atlántica, las ha colocado en posiciones de liderazgo muy visibles.

\section{Factores de trabajo contra el liderazgo de la mujeres: nacional de partidos políticos y elecciones populares}

Las mujeres de la RAAN tienen un bajo nivel de participación en el gobierno regional y municipal. Las mujeres lideresas entrevistadas afirman que las posiciones de los gobiernos elegidos por el voto popular fueron los más difíciles para las mujeres, que tienen el más bajo nivel de participación política dentro de la rama legislativa del gobierno regional. Los cuarenta cinco concejales que componen el Consejo Regional de la RAAN, que es el principal órgano legislativo constituyen los únicos miembros del gobierno autónomo cuales son elegidos por el voto popular. González, Figueroa y Barbeyto (2006, p. 16) encontró que en las primeros cuatro elecciones (1990-2006) ya que las comunidades autónomas se fundaron, la participación de las mujeres en el Consejo Regional nunca se ha adherido del 20 por ciento.

Mi investigación muestra que a partir de 2006-2010, la participación de las mujeres se desplomó a poco más del 4 por ciento. De los cuarenta y cinco concejales electos en el Consejo Regional entre 2006-2010, sólo dos eran mujeres: Juana Chow y Carlson Marisol, ambos de los cuales eran miskitu afiliadas a Yatama. Esta inequidad de género tiene importantes consecuencias, ya que el poder legislativo, guiados por el Directorio del Consejo Regional de Administración, nombra al gobernador ya todos los otros que prestan servicios en las ramas de los ejecutivos y judicial de la RAAN. Una mujer, Juana Chow, se sentó en el Directorio del Consejo Regional de Administración de 2006-2010.

La investigación realizada por González, Figueroa y Barbeyto (2006, pp. 12-13) encontró que las mujeres en la RAAN se encuentran en desventaja en las elecciones populares en los partidos políticos nacionales están involucrados. Los partidos políticos nacionales influyó en los patrones locales de votación en perjuicio de las candidatas. Afirmó que los partidos políticos nacionales con sede en Managua suelen influir en las elecciones municipales y autonómicas al optar por apoyar y proporcionar financiamiento de las campañas exclusivamente a las campañas de los hombres. Esto fue repetido por Liliette Campbell, quien dijo: "en el lado más machista es el Pacífico del país, con poder de decisión creen que las mujeres no pueden ganar elecciones". Myrna Cunningham también mencionó que los partidos nacionales colocan los nombres de las mujeres en posiciones inferiores en la papeleta de votación, lo que sugiere que las mujeres que compiten por el cargo no eran candidatos serios. Al negar el apoyo económico a las candidatas y colocar sus nombres más bajo en la boleta electoral, los partidos políticos nacionales bloquean a las mujeres para los cargos electos por voto popular. 


\section{Ideología de género local}

Las mujeres lideresas entrevistadas señalaron que la discriminación de género en el ámbito local también impide su acceso a cargos de elección popular. Las mujeres lideresas culpan tanto a hombres y mujeres locales por la votación. Se atribuyó a la cultura basadas en las percepciones de la maternidad, como miskitu y sociedades criollas en donde las mujeres tienen una visión particular y un papel primordial en la sociedad como madres y la maternidad implica ser el cuidador y vigilante de la niñez. Los Hombres miskitus y criollos y sus mujeres creen que las madres no deben exponer a sus familias a la vida pública de un político, donde las campañas negativas se lanzan contra las familias durante las elecciones públicas. Curiosamente, mientras que la maternidad se citó anteriormente como la fuente de poder de las mujeres y las habilidades de liderazgo, las percepciones locales de la maternidad, como protectores de los niños, a la vez dificulta la participación de la mujer y el éxito en las elecciones populares.

En la ejecución de un cargo público, Myrna Cunningham explicó más tarde, deja a la familia del candidato a todos, los niños incluidos abiertos a la crítica y chismes dentro de la comunidad hasta el punto donde las familias enteras pueden ser socialmente marginados. También habló de por qué las mujeres casadas no se consideran buenas candidatas en las elecciones populares: los votantes locales creen que una mujer casada al postularse para un cargo público necesita todo el apoyo emocional y económico de su esposo. Más comúnmente, la comunidad es consciente de que los hombres no soportarán a sus esposas, al negarse a entrar en los roles domésticos en el hogar. Esta situación se ha deteriorado en la discordia marital y la violencia doméstica. Además, Myrna me contó que si una mujer está casada y que actúa como un funcionario del gobierno, los locales tienden a creer que su marido influirá en su posición y decirle hacia dónde votar.

Que un marido se negaba a ayudar con las tareas domésticas, físicamente se abuse de su esposa, y controlar la forma en que se vote sobre cuestiones, parece contradictorio con el hecho de que las sociedades indígenas de miskitus y creoles se organizan en torno a patrones matrilocales residenciales y domésticas matrifocales, donde las mujeres tienen un estatus alto versus los hombres. Los Antropólogos han señalado que las relaciones ambiguas de poder existen en matrifocales grupos domésticos culturales, donde los hombres tradicionalmente mantienen la autoridad económica a través de su acceso al trabajo asalariado, y las mujeres controlar las relaciones sociales y la toma de decisiones económicas de los hogares (Menon, 1995). Este tipo de contradictorias relaciones de poder de género puede haber llevado a los altos índices de violencia intrafamiliar en la costa del Atlántico.

La violencia intrafamiliar es un problema grave en la Costa Atlántica y los miskitus tienen la tasa más alta de violencia intrafamiliar en la RAAN (Herman, 2006, pp. 
76-77). Después de la división del trabajo por género en la sociedad miskitu, el trabajo de las mujeres gira en torno a la familia, mientras que los hombres suelen trabajar por un salario. Las mujeres miskitus casadas que trabajan fuera de la casa que participan en las relaciones de género aumentan su riesgo de ser víctimas de actos de violencia cometidos por sus maridos (Olivera, 2006). Además, la violencia se normaliza en la sociedad miskitu y es visto como una parte natural del matrimonio miskitu, como la familia, la iglesia y la comunidad esperan que los hombres para corregir su esposa por comportamiento "malo" o no tradicionales (Herman, 2006: 86). Esta situación en la RAAN muestra que el derecho consuetudinario tiene efectos negativos en la vida de las mujeres todos los días y refuerza la incapacidad de las mujeres para trabajar fuera de la casa como profesionales, sirven como lideresas políticos y, sobre todo, entrar en las elecciones populares. Significativamente, las ideologías de género autóctonas para trabajar contra la participación de la mujer por la normalización política plena crea chismes en la comunidad y la violencia doméstica contra las mujeres que buscan cargos de elección popular.

La Costa Atlántica se encuentra dentro del área de cultura circum-Caribe, donde las mujeres tienen un alto estatus en la vida, mujeres centradas en los grupos domésticos, pero geopolíticamente la Costa Atlántica se coloca dentro de la región de América Latina patriarcal Estado-nación. Como resultado de ello, los discursos contradictorios y contrapuestos de las relaciones de género y poder existir. Las mujeres de la Costa Atlántica deben negociar sus identidades y estatus entre el discurso local que surge de sus grupos domésticos y de parentesco y el discurso nacional que emana del Estado Patriarcal. Las entrevistas y mi investigación muestran, sin embargo, la opresión hacia las mujeres no solamente resulta en la interacción con el Estado-nación patriarcal. Opresivas ideologías patriarcales en torno a la resolución de la percepción de la maternidad y la feminidad también se plantean en el ámbito local y regional, lo que disuade a las mujeres de entrar en posición de liderazgo.

\section{Conclusiones}

Este artículo se centra en la situación actual de las mujeres indígenas y afrodescendientes y la participación política y su acceso a puestos de liderazgo. Mi investigación exploró el proceso en el que mujeres miskitu y criollo en Nicaragua han catapultado posiciones de liderazgo en el grupo matrilocal a altos cargos políticos. Los datos recogidos en Bilwi-Puerto Cabezas demuestra que la mujeres miskitus y criollas lideresas en los últimos treinta años han accedido a puestos de liderazgo político a través de su participación con la Iglesia Morava, la revolución sandinista, y después de 1990 las organizaciones de desarrollo. Estas estapas de desarrollo político puede servir de modelo para el proceso en el que las minorías y las mujeres indígenas tienen un cuarto de género y el liderazgo en toda América Latina (Eber y Kovic, 2003). Estas etapas de empoderamiento pueden combinarse para favorecer el liderazgo de las mujeres. 
Incluso en Nicaragua es progresivo, sin embargo, donde los afrodescendientes e indígenas han logrado un éxito considerable entrando en posiciones de liderazgo, las mujeres de la RAAN alcanzan el techo de cristal durante las elecciones populares que se ven influidas por los partidos políticos nacionales optan por apoyar económicamente a los candidatos masculinos en las elecciones populares y poner su nombres en la parte superior de las papeletas. A nivel local, las campañas difamatorias y negativos son también parte integrante de elección popular. Las madres son juzgadas por la comunidad con respecto a su capacidad para proteger a sus hijos de las campañas políticas negativas. Las mujeres casadas también tienen dificultades para llegar a ser lideresas porque sus maridos a menudo se niegan a asumir la violencia doméstica, con pocas ramificaciones legales. Estos ejemplos documentan las formas en que las mujeres indígenas que viven entre las sociedades con diferentes códigos de género son tambien excluidas de los puestos de liderazgo. La autonomía basada en la tradición se combina con el patriarcal Estado-Nación para afectar negativamente el acceso de las mujeres al liderazgo político. A pesar de los avances que las mujeres han hecho de la RAAN dentro de la revolución y el movimiento autonomista indígena, las diferentes formas de discriminación contra la mujer siguen impidiendo su afirmación política y la participación en diferentes ámbitos, especialmente cuando se trata de posiciones de influencia en la toma de decisiones en los espacios nacionales y regionales. Sin embargo las Mujeres de la RAAN siguen luchando por sus derechos individuales a la participación política en la lucha por sus derechos colectivos a la autodeterminación indígena. Por lo tanto, la lucha de las mujeres en la RAAN para su participación política es parte de un nuevo feminismo indígena y emergentes en la Costa Atlántica.

\section{Lista de referencia}

Babb, F. (2001). After revolution: Mapping gender and cultural politics in neoliberal Nicaragua. Austin, Texas: University of Texas Press.

Centro de Estudios e Información de la Mujer Mulitétnica (CEIMM) (2008). Serie cuadernos de género para Nicaragua. Banco Mundial y Banco Interamericano de Desarrollo. Diagnóstico de género en las Regiones Autónomas de la Costa Caribe. Managua, Nicaragua.

Chinchilla, N. (1995). Revolutionary popular feminism in Nicaragua: Ideologies, political transitions, and the struggle for autonomy. In C. Bose and E. Acosta-Belen (Eds.), Women in the Latin American development process (pp. 242-270). Philadelphia, Pennsylvania: Temple University Press.

Collins, P. H. (1994). Shifting the center: Race, class, and feminist theorizing about motherhood. In E. Glenn, G. Chang and L. Forcey (Eds.), Mothering: Ideology, experience and agency (pp. 45-66). London: Routledge. 
Davis, S. (2006). Las mujeres valientes del Wangki Awala: Reconstruyendo nuestras almas y esperanzas. Managua, Nicaragua: URACCAN.

Eber, C. and Kovic, C. (2003). Women of Chiapas: Making history in times of struggle and hope. New York: Routledge.

Gabbert, W. (2006). Concepts of ethnicity. Latin American and Caribbean Ethnic Studies, 1(1): 85-103.

García, C. (1996). The Making of the miskitu people of Nicaragua; The social construction of ethnic identity. Acta Universitatis Upsaliensis. Studia Sociologica Upsaliensia, No. 41.

González, M., Figueroa, D., and Barbeyto, A. (2006). Género, etnia y partidos políticos en las elecciones regionales de la Costa Caribe: retos de la diversidad. Revista del Caribe Nicaragüense (WANI), No. 44:10-23.

Helms, M. (1971). Asang; Adaptation to culture contact in a Miskito community. Gainesville, Florida: University of Florida Press.

Herlihy, L. (2012). The mermaid and the lobster diver: Gender, sexuality, and money on the Miskito Coast. Albuquerque, New Mexico: University of New Mexico Press.

(2007). Matrifocality and women's power on the Miskito Coast. Ethnology, 46(2):133-150.

(2006). Sexual magic and money: miskitu women's strategies in northern Honduras. Ethnology, 45(2): 43-59.

Herman Sálomon, C. (2006). Violencia intrafamiliar y cultura: Un estudio comparativo de las comunidades étnicas de Bilwi. Tesis de maestria en Antropología Social. Universidad de las Regiones Autónomas de la Costa Caribe Nicaraguense. Managua, Nicaragua: URACCAN.

Kampwirth, K. (2001). Women in the armed struggles in Nicaragua: Sandinistas and Contras compared. In V. González and K. Kampwirth (Eds.), Radical women in Latin America: Left and right. University Park, Pennsylvania: The Pennsylvania State University Press.

Mendez, J. B. (2005). From the revolution to the maquiladoras: Gender, labor, and globalization in Nicaragua. Durham, NC: Duke University Press.

Menon, S. (1995). Male authority and female autonomy: A study of the matrilineal Nayars of Kerala, South India. In M. Maynes, A. Waltner, B. Soland and U Strasser 
(Eds.), Gender, kinship, power: A comparative and interdisciplinary history (pp. 131-145). New York: Routledge.

Mohammed, P. (1986). The Caribbean family revisited. In P. Mohammed and C. Shepherd (Eds.), Gender in Caribbean development (pp. 170-182). Jamaica: University of the West Indies.

Olivera, M. (2006). Violence against women and Mexico's structural crisis. Latin American Perspectives, Issue 147, 33(2): 104-114.

Peter Espinoza, M. (2006). Parentesco y grupo doméstico de los miskitus: Los casos de Auhya Pihni y Santa Martha. Revista del Caribe Nicaragüense (WANI), No. 44: 30- 36.

Randall, M. (1981). Sandino's daughters: Testimionies of Nicaraguan women in struggle. Vancouver, BC: New Star Books.

Wekker, G. (2006). The politics of passion; Women's sexual culture in the Afro-Surinamese diaspora. New York: Columbia University Press. 